SHS Web of Conferences 24, 01005 (2016)

DOI: $10.1051 /$ shsconf/20162401005

(c) Owned by the authors, published by EDP Sciences, 2016

\title{
Construction of traditional cultural tour landscape field based on city memory--Taking Nanjing Fuzimiao (Confucius Temple) Qinhuai Scenic Area as an example
}

\author{
Wei Zhou \\ School of Economics and Management, Nanjing Institute of Industry Technology, Nanjing, Jiangsu, China
}

\begin{abstract}
At present, traditional cultural tour sites are facing challenges in protecting city memory and inheriting regional culture under the historical background of rapid globalization and urbanization. This paper selected Nanjing Fuzimiao (Confucius Temple) Qinhuai Scenic Area as a microcosmic case to study city memory. It explained the theoretical connotation of landscape field by literature collecting, field research, and interview. It also conducted empirical study in material cultural landscape and non-material cultural landscape, and tried to establish a landscape field of traditional cultural tour sites, so as to promote the scientific planning and healthy development of traditional cultural tour sites, and provide scientific basis and valuable experience for the prosperity of Chinese national culture.
\end{abstract}

Keywords: city memory; traditional cultural tour sites; landscape field; Nanjing Fuzimiao (Confucius Temple) Qinhuai Scenic Area

\section{INTRODUCTION}

Traditional cultural tour sites in cities have gone through development of different times. It contains rich history information, combines multi-culture elements, and has become the spatial field of protecting city memory and manifesting urban locality charm. However, with the rapid development of globalization and urbanization, reconstruction of old city and construction of new town have been in continuous acceleration. Accordingly, the conflict between the development of urban construction and the lack of city memory is becoming more and more serious. Traditional cultural tour sites are in constant shortage of city memory and cultural inheritance. At the moment, domestic and overseas scholars prefer to conduct empirical study on cultural tour sites of different types from the perspectives of tour site attribute, tour site image, tourism development, tourism perception and experience, tour description, cultural protection, and stakeholders ${ }^{[1-7]}$. Some scholars have researched the differentiation features and rules ${ }^{[8]}$ of post-tourism perception dimensionality in cultural tour sites from the perspective of city memory. Nonetheless, the empirical analysis made from the perspective of landscape field construction is relatively weak. Therefore, this study selected a traditional cultural tour site as a microcosmic case to explain the theoretical connotation of landscape field from the perspective of city memory, and to conduct empirical study on the landscape field construction of traditional cultural site from both material and non-material cultural landscape perspectives, so as to improve the city memory protection function of traditional cultural tour site, promote the scientific planning and healthy development of traditional cultural tour sites, and provide scientific basis and valuable experience for the prosperity of Chinese national culture.

\section{CONNOTATION INTERPRETATION OF LAND- SCAPE FIELD}

The very early appearance of Landscape was in The Old Testament of Hebrew Bible. It was used to describe the magnificent view of Solomon Imperial City (Jerusalem $)^{[9]}$. After that, the paraphrase and research category of landscape have been expanded while aes- 
thetics, architecture, geography, sociology, landscape ecology and urban planning have been integrated into landscape. For example, O. C. Sauer, an American human geographer, once presented the difference between natural landscape and human landscape. He thinks natural landscape refers to the original landscape of the districts where humans have not stepped in while human landscape refers to the landscape changed by humans. In fact, as a combination of natural attribute and human attribute, the connotation and denotation of landscape are very rich. They are more likely about the heritage objects of various categories, such as historic space, cultural places and locality. To make it more specific, the heritage objects of traditional cultural sites mainly include material cultural landscape and non-material cultural landscape, among which material cultural landscape includes historic architectural complexes, landscape remains, and former residences of celebrities bearing simple and unsophisticated styles and features where most tourists have "off-site" perception experience. According to the above analysis, this study refers to the conception of "field" in physics (The conception of "field" in physics is a physical quantity taking space-time as the variable.), and makes further analysis of the city memory elements contained in traditional cultural sites. It constructs the landscape field from two perspectives: material cultural landscape and non-material cultural landscape. Consequently, vivid historical scenes can be represented while historic buildings and landscape styles can be conserved in the meantime. It is able to created rich historic cultural atmosphere, establish local cultural living flavor full of warmth, satisfy tourists' needs in aesthetic appreciation and recreation to the utmost extent and improve the functions of city memory and cultural inheritance born in traditional cultural sites.

\section{PLACE OF CASE STUDY}

Nanjing Fuzimiao (Confucius Temple) Qinhuai Scenic Area was officially identified as the first 5A open-style scenic spot of China in 2010. It has obtained high reputation and influence in tourism at home and abroad. Nanjing Fuzimiao (Confucius Temple) Qinhuai Scenic Area has gone through three different development phases - ancient times, modern times, and contemporary times. It has witnessed the vicissitudes of Nanjing which was the ancient capital. Although it contains important city memory function, locating in the core part of urbanization in Nanjing old city, Fuzimiao (Confucius Temple) Qinhuai Scenic Area has been suffering from continuous shortage of traditional cultural elements, gradual extinction of locality features, and reduction of city memory protection with the acceleration of urban renewal in recent years. Due to its failure to meet the standards in tourism security management, environmental health, ser- vice quality, and market order, Nanjing Fuzimiao(Confucius Temple) Qinhuai Scenic Area 5A scenic spot received warning from the National Tourism Administration in 2015. As a typical representative of traditional cultural tour sites, the historic landscape of Fuzimiao Qinhuai Scenic Area has been well conserved; however, negative problems have emerged endlessly during urban development and change. Therefore, the selection of this case contains high typicality and representativeness.

\section{CONSTRUCTION OF TRADITIONAL CUL- TURAL TOUR LANDSCAPE FIELD BASED ON CITY MEMORY}

\subsection{Extraction of city memory element}

By looking up historical documents and materials, carrying out several field surveys in the case site, and interviewing local permanent residents, this study has collected mass data of Fuzimiao Qinhuai Scenic Area and summarized the city memory elements contained in the case site as shown in Table 1.

\subsection{Construction of material cultural landscape field}

The city memory elements which are related to material cultural landscape and listed in Table 1 include historical buildings, landscape remains, Qinhuai food, century-old food shops, and old names of streets and lanes. They have long historical standings and distinct local features. Local residents, especially permanent residents, have deep memory of those city memory elements. Therefore, this study tries to propose the following strategies from the perspective of constructing material cultural landscape field.

\subsubsection{Remains of historical buildings and landscape: authenticity protection and "activation"}

Although the historical buildings and landscape remains in the case site have been well repaired and the traditional architectural styles in Ming and Qing Dynasties have been maintained in appearance, single and static exhibition method cannot motivate tourists' major interest. As a result, "activation" of historical buildings and landscape remains shall be carried out while insisting on authenticity protection. Change static exhibition into dynamic participation and mutual experience to"activate" memory elements. Take the ancient bridges on Qinhuai River as examples. Most of the bridges have rich historic and cultural connotation as mentioned in the line "grass flowers growing beside Zhuque Bridge with setting sun hanging above the entrance of Wuyi Lane" describing Zhuque Bridge and phrases such as "childhood sweetheart" and "intimacy of childhood" describing Changgan Bridge all of which were beautiful lines and phrases wining universal praise. For this reason, those ancient bridges are 
Table 1. Type of Fuzimiao (Confucius Temple) Qinhuai Scenic Area and extraction of city memory element

\begin{tabular}{|c|c|c|}
\hline Landscape type & Memory element type & Content of memory element \\
\hline \multirow[t]{3}{*}{$\begin{array}{l}\text { Material cultural } \\
\text { landscape }\end{array}$} & 1. landscape remains & $\begin{array}{l}\text { Jiangnan Examination Hall**, Dacheng Hall, academy*, Lingxing } \\
\text { Gate, Juxing Pavilion, Kuiguang Pavilion, TianxiaWenshu Lane, } \\
\text { Fuzimiao Memorial Archway, Wende Bridge*, Dazhao Wall, Wuyi } \\
\text { Lane, Wuyi Ancient Well }{ }^{\circledR} \text {, Madam Fengshengzhi Monument }{ }^{*} \text {, Feng- } \\
\text { sishi Monument*, Qinhuai River, Dongshuiguan, Xishuiguan, Wuyi } \\
\text { Lane, historical site of Taoye Ferry, Zhan Garden, Bailuzhou Park, } \\
\text { Zhonghua Gate Castle, The Porcelain Tower, Wende Bridge*, } \\
\text { Wenyuan Bridge, Wenzheng Bridge, Huaiqing Bridge, Zhenhuai } \\
\text { Bridge, Zhuque Bridge, Pingjiang Bridge, Laiyan Bridge, former } \\
\text { residence of Xiangjun Li, former residence of Dashi Qin, and former } \\
\text { residence of Xie Wang, etc. }\end{array}$ \\
\hline & $\begin{array}{l}\text { 2. Featured food shops in } \\
\text { Fuzimiao }\end{array}$ & $\begin{array}{l}\text { Century-old food shops such as Jinling duck blood and vermicelli } \\
\text { soup, Master bean, and Jiangyoujiguotie stuffed with beef. }\end{array}$ \\
\hline & $\begin{array}{l}\text { 3. Old names of streets and } \\
\text { lanes }\end{array}$ & $\begin{array}{l}\text { Jiankang Road, Longmen Street, Jinling Road, Zhuangyuanjing, } \\
\text { Gongyuan Street, West Gongyuan Street, Dashiba Street, Pingjiangfu } \\
\text { Road, etc. }\end{array}$ \\
\hline \multirow{3}{*}{$\begin{array}{l}\text { Non-material } \\
\text { cultural landscape }\end{array}$} & $\begin{array}{l}\text { 1. Historical literature } \\
\text { works }\end{array}$ & $\begin{array}{l}\text { A Dream in Red Mansions, Padding Sound in the Qinhuai River, and } \\
\text { The Peach Blossom Fan, etc. }\end{array}$ \\
\hline & $\begin{array}{l}\text { 2.Festival entertainment } \\
\text { activities }\end{array}$ & $\begin{array}{l}\text { Qinhuai lantern show }{ }^{* * *} \text {, float river lanterns and fly kites on } \\
\text { Tomb-sweeping Day, Fuzimiao Gourmet Festival, temple fair, and } \\
\text { Qinhuai barge tour, etc. }\end{array}$ \\
\hline & $\begin{array}{l}\text { 3. Folk-custom perfor- } \\
\text { mance }\end{array}$ & $\begin{array}{l}\text { Folk art showplace, Qinhuai colored-lantern making }{ }^{* *} \text {, making skills } \\
\text { of featured Qinhuai snacks }{ }^{*} \text {, Nanjing paper-cut }{ }^{* * *} \text {, knotting, diabolo } \\
\text { (buzz) }{ }^{*} \text {, dough modeling, Nanjing Baiju (an old-aged Chinese folk art } \\
\text { form) })^{* * *} \text {, Nanjing cross talk }{ }^{*} \text {, and Nanjing popular stores }{ }^{*} \text {, etc. }\end{array}$ \\
\hline
\end{tabular}

Note: (1) “**”refers to provincial-level culture relic protection site; “*” refers to city-level culture relic protection site.

(2) “***"refers to being selected in national-level non-material cultural heritage protection list; “**” refers to being selected in provincial-level non-material cultural heritage protection site; "*" refers to being selected in city-level non-material cultural heritage protection site.

the symbol marks recording the historical changes of Qinhuai River. While protecting and repairing the ancient bridges, dynamic scene of "still humans \&vivid bridges" can be appropriately manifested in the following ways: hang Qinhuai colored lanterns or red lanterns on each end of bridge masts and use varicolored lighting for brightening and rendering at night, and carry out water entertainment and athletic activities such as "dragon rise", "dragon water spouting" and "dragon-boat racing" with the popularity gathered by the ancient bridges to enhance interaction and participation. Take former residences of celebrities which are the carriers for tourists to perceive the past for examples. Most tourists only take a glance at the residences and have little impression of them. Therefore, it can be considered to combine eminent persons in history, historical stories, former residences of celebrities, and historical memory all together in tour route design. Arrange regular "Qinhuai barge cruise" each day. Carry out a series of activities such as "wander in Qinhuai barge, appreciate Qinhuai night view, taste Qinhuai boat feast, listen to JinlingBaiju, visit former residences of celebrities, watch live-action perfor- mance, and enjoy misty rain of the six dynasties" with the docking function of the barge to enhance tourists' memory of local historical allusions, anecdotes of famous persons, and changes of the six dynasties.

\subsubsection{Century-old food shops: innovation}

Through field surveys, it has been found that many foreign tourists come to Fuzimiao to try local food because of its fame; however, most tourists still prefer modern fast food or western food shops when they arrive. There are two main reasons for this phenomenon: One is that many local old and famous food shops have been removed from the scenic area; the other is modern food and chain stores of fast food spread all over the scenic area with obvious nameplates and comfortable dining environment. As a result, the recovery of "century-old" food shops is not only about rebuilding the brands of "Qinhuai Eight Must", "Wanqing House", "Jinling Duck Blood and Vermicelli Soup", and "Jiangyouji" fried dumpling, it is more about bringing local flavor into people's daily life and turning them into convenient catering consumer goods. The methods to reach this goal includes establishing online and offline operation pattern, en- 
hancing the publicity of food shops by applying modern information technology, building online marketing channels such as Wechat, microblog and online BBS, and arranging promotion or discount of different forms for online followers such as distributing network discount coupons, planning "foretaste" activities, offering more discount for more consumption or persons' collaboration, in order to integrate online promotion and offline marketing; represent the prosperity of "century-old shops"; and help people find the old taste in their memory.

\subsubsection{Old names of streets and lanes: respect and protection}

Old names of streets and lanes are important carriers of carrying on street texture and maintaining street space relations. To some extent, they are the landscape symbols with cultural symbolic function. Some of the existing old place names in the case site are related to the ancient bridges, such as Laiyan Road and Changganli while some are related to former residences or relics of celebrities, such as Wuyi Lane and Taoye Ferry. Therefore, besides name conservation and maintenance of historical street texture, it is more important to dig out the historical facts of street and lane changes in protecting the old names of streets and lanes. The heritage of old place names contains local cultural connotation. We shall implement "active-state" heritage of the old place names bearing urban history, local culture, and ordinary folk-custom living atmosphere. For this reason, while collecting and filing old place names, it is also required to derive and represent historical scenes. For example, TaoyeFerry, was Wang Hsi-Chih, a famous calligrapher, and his favorite concubine Ye Tao's dating site, thusthe publicity of this old place name can be based on it. As another example, "Old Place Name" calligraphy landscape contest or "Old Place Name" treasure hunt network competition can be held to expand the popularity of the old place names and manifest the rich historical cultural deposits of Fuzimiao (Confucius Temple) Qinhuai Scenic Area.

\subsection{Construction of non-material cultural landscape field}

Besides various material cultural landscape with embodiment features which can be seen, appreciated, and touched in traditional cultural tour sites, non-material cultural landscape is also an important carrier in inheriting historical memory, including historical literature works, leisure and recreation activities, folk-custom performance, and festival activities listed in Table 1. Therefore, the construction of non-material cultural landscape field shall excavate the city memory elements contained in non-material cultural heritage landscape, change the original landscape exhibition method that is single and static and combine culture with leisure, recreation, tourism, technology, and in- novation. Tourists' recreation experience function can be enhanced while their memory and impression can be deepened if the static visit can be turned into dynamic experience and the passive sightseeing can be turned into active participation.

\subsubsection{Historical literary works: creative efforts} Many literary works, such as A Dream in Red Mansions, Padding Sound in the Qinhuai River, and The Peach Blossom Fan, describe historical scenes related to FuzimiaoQinhuai River. Renowned literature masters write those works. Their content is not only close to common people's life, but also has rich historic culture. For example, A Dream in Red Mansions written by Xueqin Cao, a writer in Qing Dynasty, is one of the four Chinese famous classic works. As a novel describing human feelings and possessing worldwide influence, it is honored as a peak piece of Chinese classic novels. A Dream in Red Mansions is an encyclopedia reflecting Chinese feudal society and epitomizing Chinese traditional culture. The love stories and humanity stories among the leading character BaoyuJia and the Twelve Ladies of Jinling described in the novel are from the historical scenes surround FuzimiaoQinhuai River, reflecting the local historical changes happened in the last phase of feudal society. For another example, Padding Sound in the Qinhuai River is a lyric prose with depictioin of scenery. It is written by essayist Ziqing Zhu. Padding Sound in the Qinhuai River starts with the essayist and his friend's visit to Qinhuai River during which they hired "Qibanzi". It takes "padding sound and lantern shadow" as the clues to describe the beautiful night view and prosperous scene of Qinhuai River from Lishe Bridge to the outside part of Dazhong Bridge and from sunset to moonlight. Moreover, it confirms that Qinhuai River gathered a lot of poets and literary men in history. Hence, the heritage of the historical memory of FuzimiaoQinhuai River can be carried out to praise the studies of Chinese ancient civilization. Repack those historical monumental works with rich cultural connotation and combine them with modern elements. Release collected papers of the Twelve Ladies of Jinling, paper-cuts of Qinhuai Bayan (eight well-known prostitutes), series bookmarks of A Dream in Red Mansions, comic strips of The Peach Blossom Fan, rain flower stone carving and sculptures of A Dream in Red Mansions, and other exquisite handworks or tourist souvenirs to advertise the local culture of Nanjing and reduce the hidden danger of the cutthroat competition among tourist souvenirs to some extent.

\subsubsection{Festival entertainment activities: build the living atmosphere of ordinary folk custom}

Festival entertainment activities are important carriers to promote the culture of tour site and continue city's vitality. As a national-level non-material cultural heritage program, Qinhuai Lantern Show has been con- 
tinued since ancient times and now is a folk-custom activity with particular charming in Nanjing. As the old saying goes, "A sprig festival cannot be called a spring festival if you haven't watched the lantern show in Fuzimiao; a spring festival cannot be called a happy spring festival if you haven't bought any lantern in Fuzimiao", Qinhuai Lantern Show owns very important status in Nanjing residents' mind. As a provincial-level non-material cultural heritage program, Qinhuai colored-lantern making is not only an important school in our traditional colored-lantern making art, but also a folk art with the most representative locality. Qinhuai colored-lantern making art was mainly distributed in the Qinhuai River basin of Nanjing in history and conducted in family workshops. After Ming Dynasty, Qinhuai colored-lantern making was mainly concentrated in Pingshi Street, Shangxin River, and on both sides of "Ten-Mile Qinhuai". Till now, countless local residents and foreign tourists will come to visit on Lantern Festival each year. It is undeniable that more and more local residents are showing less enthusiasm. It is known from investigation and survey that parts of the young people in Nanjing are starting to be unaccustomed to visiting Fuzimiao. In their eyes, Fuzimiao is too crowded with too many lanterns on Lantern Festival. Some local senior citizens sigh that the prosperous lantern show is gone. Few people will watch full-scale drama, have stall tea, or get together for chatting. It is hard to have artists playing their unique skills in the street. A handmade colored lantern can cost several hundred yuan now, not as worthy as before. More foreign tourists are disappointed to see a large crowd of people while their expectation is to enjoy lanterns. As a result, the inheritance of Qinhuai Lantern Show must contain non-material heritage culture and the "activation" elements of city memory. It is practical to promote a new tourist route of Qinhuai barge tour with the theme of Qinhuai Lantern Show. Connect the scenic spots of Zhan Garden (lantern appreciation \& lantern making)-Fuzimiao Scenic Area (lantern start \& lighting)-relics of Taoye Ferry (romance lights)-Bailuzhou Park (scenery appreciation with lanterns)-Zhonghua Gate Tower (find lotus lantern) together and arrange "lantern appreciation and making" activity in Zhan Garden, including activities of guessing lantern riddles, colored lantern artist's live performance, and lantern-making skill teaching. Conduct "lantern start" ceremony on the Miaoqian Square in front of Fuzimiao Scenic Area to carry Confucian culture and imperial examination culture forward. According to appropriate tourist groups' features, arrange "romance lighting" ceremony in the relics of Taoye Ferry. Lovers can fly their lanterns here and have their best wish of love symbolized in the lanterns. Organize theme lantern show of finding "lotus lantern". In this way, the activity range of lantern show can be expanded. Tourists can have richer tourism perception and experience which can help them realize the Qinhuai cultural deposits inherited in the lantern show.

\subsubsection{Folk-custom performance: representation of prosperous folk-custom scene}

Folk-custom performance and activities were flourishing around the FuzimiaoQinhuai Scenic Area in history, such as paper-cut, knotting, playing diabolo, dough modeling, Baiju, Qinhuai Lantern Show, temple fair, and floating river lanterns on Tomb-sweeping Day. They received great affection from the common people. At present, these folk-custom performances and activities are mostly given in the Folk Art Grand Garden with few tourists and only some local residents to pay a visit. In history, it was a place for common people to get together and chat. Folk artists were free to perform their unique skills here (Figure 1). However, visitors need to pay to enter the garden now. Non-material cultural heritage works are mostly in static exhibition in the garden which tourists have little interest in. For this reason, as important experience space of non-material cultural heritage, the Fork Art Grand Garden shall recover the prosperous scene in history. It can refer to the scene in A Dream in Red Mansions and design historical exhibition performance such as "grandmother Liu's Entrance in Grand Garden" to attract more tourists. It shall be considered to add appropriate recreation facilities for local residents, including building some teahouses or theaters to enjoy local operas such as Nanjing Baiju. "Folk-Custom Entertainment and Performance Hall" can also be constructed. Experience-oriented folk-custom cultural tourism programs with multiple participation, such as dragon's leaping over turtle, sparrow pulling, kicking Diezi, frog fight (they are all names of local games), and other interesting little games with dragon lantern dance, fish-lantern, bamboo hobbyhorse lantern, snipe lantern, local drama and

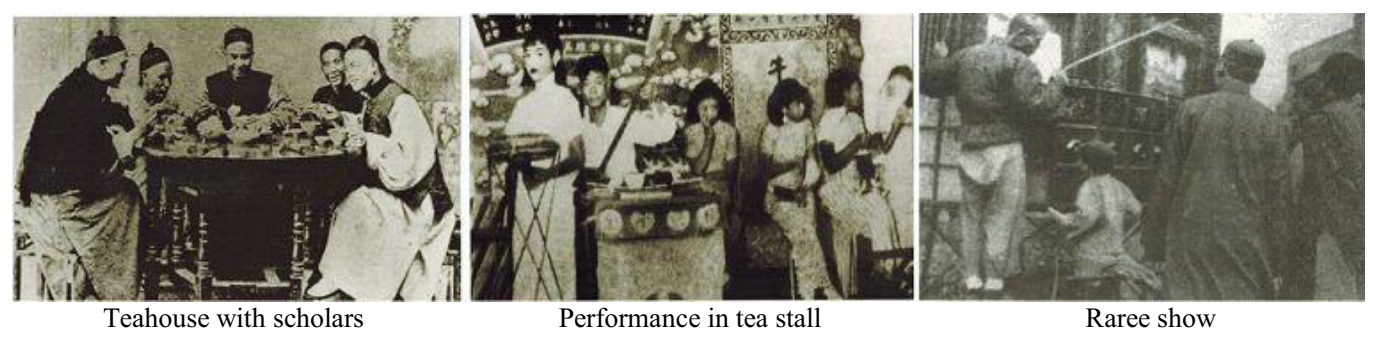

Figure 1. Civilian activities around the Folk Art Grand Garden in history. 


\section{SHS Web of Conferences}

folk variety show shall be organized to attract the attention from local residents and foreign tourists, enhance their tourism experience and satisfy their needs in reminiscence. The grand garden can also invite some famous folk-custom artists to perform or teach their unique skills at site periodically for visitors to participate in folk art establishment. As a result, the visitors' interest in travelling here will be greatly enhanced, and the Folk Art Grand Garden will become a "Spring Garden" of gathering the local folk custom in Nanjing.

\section{CONCLUSION}

Under the historical background of rapid globalization and urbanization, traditional cultural tour sites are facing challenges in protecting city memory and inheriting regional culture. This study selected Nanjing Fuzimiao (ConfuciusTemple) Qinhuai Scenic Area as a microcosmic case to further extract the abundant memory elements stored in the case from the angle of city memory. Based on the case, this study integrated the protection of city memory elements into the landscape field construction of traditional cultural tour site by explaining the theoretical connotation of landscape field, that is to implement authenticity protection and "activation" for historical buildings and landscape remains, carry out innovation for century-old food shops, and respect and conserve the old names of streets and lanes from the perspective of material cultural landscape; and to make creative efforts in repacking historical literature works, enrich festival entertainment activities by creating ordinary folk custom living atmosphere, and reappear the prosperous scene of folk custom by offering folk-custom performances.

This study only selected Nanjing Fuzimiao (ConfuciusTemple) Qinhuai Scenic Area as a typical case of traditional cultural tour site to conduct further exploratory research. To analyze from the wide range of the study, historic villages, ethnic villages and ancient water towns can also be selected as the study cases for deep analysis and comparative study. They will also become the directions of future research.

\section{ACKNOWLEDGEMENT}

This paper has obtained joint fund from the National Natural Science Foundation of China (No.41401152), Youth Fund of Humanities \& Social Sciences of Ministry of Education (No.14YJCZH228); the Funding Project for Domestic Senior Visiting Scholar Plan of Jiangsu Higher Vocational Colleges (No.2015FX036), and the Major Subject in Humanities \& Social Sciences of Nanjing Institute of Industry Technology (No.YK13-05-03).

\section{REFERENCES}

[1] Yang, Z.P., Xie, T \& Li, X.Y. 2001. Development and conservation of representative minority culture sightseeing district--Taking Kashi prefecture as an example. Arid Land Geography, 24(4): 332-337.

[2] Min, Q.W., Zhang, D. \& He. L. et al. 2011. Major Process in China's Agricultural Heritage Studies and Conservation Practice, 33(6):1018-1024.

[3] Park D C. \& Coppack P M. 1994. The role of rural sentiment and vernacular landscapes in contriving sense of place in the city's countryside, 76(3): 161-172.

[4] Zhou W., Huang, Z.F., Cao, F.D., Wu, L.M. \& Liang, Y.Y. 2013. The Driving Effects Attached by Theme Cultural Tour Site Attribute on Tourist Site--Taking Chunqiu Yancheng Tourist Area of Changzhou as an Example, 32(8): 1528-1540.

[5] Azaryahu M. \& Kellerman A.1999. Symbolic places of national history and revival: A study in Zionist mythical study, 24(1): 109-123.

[6] Chen, J.P. 2006. Tour description system of cultural tourist site and analysis of its building, 6(6): 38-40, 46

[7] Tan S., Song, L.Z. \& Zhou, S.L. 2010. Development pattern analysis of foreign cultural tour site based on stakeholder's angle of view and its enlightenment, 32(3): 20-29.

[8] Zhou, W., Huang, Z.F., Tang, W.Y. \& Shen, S.Y. 2014. Post-Tourism Perception Dimension Differentiation of Cultural Tour Site Based on City Memory--Taking Nanjing Fuzimiao (Confucius Temple) Qinhuai Scenic Area as an Example, 29(3): 73-83.

[9] Yu, K.J. 2002. The Meaning of Landscape, 21(1): 14-17. 